\title{
Special Issue Introduction: Teaching the General Linear Model
}

\section{Rafael Antonio Garcia \\ University of Arizona}

\author{
Melinda F. Davis
}

Keywords: General Linear Model, quantitative training

In his 1968 article, Jacob Cohen demonstrated that ANOVA is a special case of regression analysis, both are part of the same general linear model (GLM). Unfortunately, quantitative instruction in psychology has not yet embraced the GLM. In 2015, Richard Gorsuch notes that "We now have the ingredients to bring the elegance of the 1975 full into teaching and doing statistics. It would be nice to have students learn the late 2oth century paradigm for use in the 21st century." (Gorsuch, 2015, p. 68)

\section{References}

Cohen, J. (1968). Multiple regression as a general data-analytic system. Psychological Bulletin, 70, 426-433.

Gorsuch, R. L. (2015). Enhancing the Teaching of Statistics by Use of the Full GLM. Journal of Methods and Measurement in the Social Sciences, 6, 60-69. 